\title{
Review Article \\ Relationships between Global DNA Methylation in Circulating White Blood Cells and Breast Cancer Risk Factors
}

\author{
Nayha Chopra-Tandon, ${ }^{1}$ Haotian Wu, ${ }^{2}$ Kathleen F. Arcaro, ${ }^{3}$ and Susan R. Sturgeon ${ }^{1}$ \\ ${ }^{1}$ Department of Biostatistics and Epidemiology, School of Public Health and Health Sciences, \\ University of Massachusetts, Amherst, MA, USA \\ ${ }^{2}$ Department of Environmental Health Sciences, School of Public Health and Health Sciences, \\ University of Massachusetts, Amherst, MA, USA \\ ${ }^{3}$ Department of Veterinary and Animal Science, College of Natural Sciences, University of Massachusetts, Amherst, MA, USA
}

Correspondence should be addressed to Nayha Chopra-Tandon; nchoprat@umass.edu

Received 22 October 2016; Revised 26 February 2017; Accepted 14 March 2017; Published 6 April 2017

Academic Editor: Yun-Ling Zheng

Copyright (C) 2017 Nayha Chopra-Tandon et al. This is an open access article distributed under the Creative Commons Attribution License, which permits unrestricted use, distribution, and reproduction in any medium, provided the original work is properly cited.

\begin{abstract}
It is not yet clear whether white blood cell DNA global methylation is associated with breast cancer risk. In this review we examine the relationships between multiple breast cancer risk factors and three markers of global DNA methylation: LINE-1, 5-mdC, and Alu. A literature search was conducted using Pubmed up to April 1, 2016, using combinations of relevant outcomes such as "WBC methylation," "blood methylation," "blood LINE-1 methylation," and a comprehensive list of known and suspected breast cancer risk factors. Overall, the vast majority of reports in the literature have focused on LINE-1. There was reasonably consistent evidence across the studies examined that males have higher levels of LINE-1 methylation in WBC DNA than females. None of the other demographic, lifestyle, dietary, or health condition risk factors were consistently associated with LINE-1 DNA methylation across studies. With the possible exception of sex, there was also little evidence that the wide range of breast cancer risk factors we examined were associated with either of the other two global DNA methylation markers: 5-mdC and Alu. One possible implication of the observed lack of association between global WBC DNA methylation and known breast cancer risk factors is that the association between global WBC DNA methylation and breast cancer, if it exists, is due to a disease effect.
\end{abstract}

\section{Introduction}

A CpG site, a cytosine followed by a guanine, has the potential to be methylated, and measuring 5-methyl-2' deoxycytidine (5-mdC) content across the genome by liquid chromatography/mass spectrometry (LC/MS) can provide an overall measure of genome-wide DNA methylation levels. Repetitive sequences of the genome such as LINE-1 and Alu contain up to half of all DNA methylation in the genome [1]. Thus, measuring DNA methylation levels in LINE-1 or Alu repetitive elements by pyrosequencing or Methyl Light is often used as a surrogate higher-throughput approach to assess genome-wide methylation [2]. Genome instability has been associated with DNA hypomethylation and such global loss of methylation is common in breast tumor tissue [3-7].

There is some evidence that peripheral white blood cell (WBC) DNA contains epigenetic information that can be used to assess an individual's risk of breast cancer. In a casecontrol study of breast cancer of 179 cases and 180 controls, Choi and colleagues observed a nearly threefold increase in risk among women in the lowest tertile of total 5-mdC levels in WBC DNA compared to women in the highest tertile [1]. In the NIEHS sister case-cohort study of 294 cases and 646 noncases in which the mean time between blood collection and breast cancer diagnosis was 15 months [8], LINE-1 methylation percentage in WBC DNA was also inversely associated with the risk of breast cancer, with a nearly twofold increased risk observed among women in the lowest quartile compared with those in the highest quartile. However, Brennan and colleagues reported no association between LINE-1 WBC methylation and breast cancer risk in three prospective nested case-control studies [9]. Several other case-control studies, ranging in the number of breast cancer cases from 19 to 1064, found no association between 
LINE-1 methylation and breast cancer risk [1, 10-12] or between Alu methylation and breast cancer risk $[12,13]$.

The LUminometric Methylation Assay (LUMA) measures levels of 5-mdC in a specific CmCGG motif which is found both in promoter regions of the genome and in repetitive elements [11]. Interestingly, one case-control study reported a twofold increase in risk of breast cancer among women with higher 5-mdC content compared to those with lower levels measured by LUMA. Another study reported no association [14] and a third study reported a strong inverse association between increasing tertiles of LUMA methylation and breast cancer risk [15].

It is not yet clear whether WBC DNA global methylation is associated with breast cancer risk [16]. If there is an association, one possible explanation is that the association represents environmental and lifestyle determinants of breast cancer that influence both DNA methylation and breast cancer risk. An alternative possibility is that, in response to very early breast cancer, a new clone of circulating lymphocytes arises that alters white blood cell DNA methylation [17]. If WBC DNA methylation is a marker of exposure associated with breast cancer risk, rather than a marker of early disease, it is reasonable to expect that white blood cell DNA methylation patterns would be more likely to be correlated with hormonal and other established or suspected risk factors for breast cancer. Terry and colleagues [18] reviewed literature up to 2011 on the relation between WBC DNA methylation patterns and a number of cancer risk factors. As the literature has expanded substantially, we updated the review, focusing on four demographic factors (age, sex, race/ethnicity, and education), three lifestyle factors (alcohol, smoking, and physical activity), three dietary factors (BMI, vegetable intake, and fruit intake), and eight health history and reproductive factors (menopause status, fetal birth weight, family history of breast cancer, age at menarche, age at first birth, parity, hormone replacement therapy, and endogenous hormones) that have been associated with breast cancer [19]. We also included folate in our review because although results have been mixed for breast cancer, folate is plausibly linked to DNA methylation [20]. We examined the relationships between these breast cancer risk factors and three markers of global DNA methylation: LINE-1, 5-mdC, and Alu. Our review comprises literature published through April 2016 and includes over 30 new studies that were not included in the 2011 review [18].

\section{Methods}

A literature search was conducted using Pubmed up to April 1, 2016. Searches were performed using combinations of relevant outcomes such as "WBC methylation," "blood methylation," "blood LINE-1 methylation," and a comprehensive list of known and suspected breast cancer risk factors such as "diet," "physical activity," and "menopause." Boolean operators "and" and "or" were used whenever appropriate. Titles and abstracts were screened to determine relevancy by three independent reviewers. Additionally, bibliographies of select reviews were screened to ensure capture of all relevant information and ideas. If relevancy could not be determined from the abstract, the full text was retrieved to ensure comprehensive capture.

A study was included if it was primary research, published in English, and contained relevant results on any risk factor and blood DNA methylation outcomes. Studies were included that had both men and women due to the limited number of studies performed only in women. Studies were only included if their data were based on populations of nondiseased individuals.

\section{Results}

Table 1 shows the number of studies reporting associations between global WBC DNA methylation and demographic, lifestyle, dietary, and reproductive factors for each of three markers (i.e., LINE-1, Alu, and 5-mdC). Overall, the vast majority of reports in the literature have focused on LINE1. For example, 21 studies examined the association between age and LINE-1 but only four studies examined age and 5mdC. There were ten or more studies that each examined the association between LINE-1 and alcohol, smoking, body mass index, vegetables, and folate. Fewer studies were available for $A l u$ and 5-mdC and for reproductive risk factors.

\subsection{Demographic Factors}

3.1.1. Age. As shown in Table 2, twenty of the twenty-one studies examining $L I N E-1$ reported no significant association between age and LINE-1 methylation levels [11, 21-38]. Only one study reported a significant association between increasing age and higher LINE-1 methylation levels [29]. Three of the six studies examining Alu methylation found no significant association with age [38, 41, 42], while the other three studies reported a significant association between increasing age and decreasing Alu methylation [22, 39, 40]. Two of four studies examining 5-mdC levels did not find a significant association with age $[1,44]$, while two other studies reported a statistically significant association between increasing age and decreasing 5-mdC levels [39, 43]. In summary, of the 31 studies with data on age and estimates of global DNA methylation no relationship was reported for 25 of the studies, a significant inverse relationship was reported for five studies, and a positive relationship was found in only one study.

3.1.2. Sex. As shown in Table 2, eleven of the seventeen studies reported statistically significant higher LINE-1 levels in males than in females [25, 28-30, 32, 34-36, 42, 45, 46], while the other six studies found no statistically significant association between sex and LINE-1 levels [23, 27, 33, 37, 38, 47]. Two studies found no significant association between sex and Alu methylation [38, 40] while two other studies found a significant association for higher Alu methylation in males than in females $[42,48]$. One study showed a significant association for higher 5-mdC levels in males than in females [43]. In summary, of the 22 studies with data on sex and estimates of global DNA methylation no relationship was reported for eight of the studies, and significant inverse relationship was reported for fourteen studies. 
TABLE 1: Summary of number of reports by risk factor and global methylation measure.

\begin{tabular}{|c|c|c|c|c|}
\hline Factors & Total \# of reports & LINE-1 & Alu & 5-mdC \\
\hline \multicolumn{5}{|l|}{ Demographic Factors } \\
\hline Age & 31 & 21 & 6 & 4 \\
\hline Sex & 22 & 17 & 4 & 1 \\
\hline Race/ethnicity & 6 & 5 & 0 & 1 \\
\hline Education & 7 & 6 & 0 & 1 \\
\hline \multicolumn{5}{|l|}{ Lifestyle factors } \\
\hline Physical activity & 5 & 5 & 0 & 0 \\
\hline Alcohol & 17 & 13 & 3 & 1 \\
\hline Smoking & 22 & 16 & 4 & 2 \\
\hline \multicolumn{5}{|l|}{ Dietary factors } \\
\hline BMI & 17 & 13 & 3 & 1 \\
\hline Vegetables & 11 & 11 & 0 & 0 \\
\hline Fruit & 6 & 6 & 0 & 0 \\
\hline Folate & 13 & 12 & 0 & 1 \\
\hline \multicolumn{5}{|l|}{ Reproductive factors } \\
\hline Menopause status & 2 & 1 & 0 & 1 \\
\hline Fetal birthweight & 1 & 1 & 0 & 0 \\
\hline Family history of breast cancer & 6 & 4 & 1 & 1 \\
\hline Age at menarche & 1 & 0 & 0 & 1 \\
\hline Age at first birth & 1 & 0 & 0 & 1 \\
\hline Parity & 1 & 0 & 0 & 1 \\
\hline Hormones & 4 & 3 & 0 & 1 \\
\hline
\end{tabular}

3.1.3. Race/Ethnicity. Five studies investigated the association between LINE-1 methylation and race/ethnicity (Table 2). Non-Hispanic Blacks had a significantly lower LINE-1 level compared to non-Hispanic Whites [36] in one study, whereas the reverse was observed in two studies [28, 34]. Two other studies showed no significant association between race/ethnicity and LINE-1 levels [11,37]. One study showed no significant association between race/ethnicity and 5mdC levels [1]. In summary, of the six studies with data on race/ethnicity and estimates of global DNA methylation no relationship was reported for three of the studies, non-Hispanic Blacks had a significantly lower global DNA methylation compared to non-Hispanic Whites in one of the studies, and the inverse relationship was reported for two of the studies.

3.1.4. Education. As shown in Table 2, all six studies examining LINE-1 that included education as a risk factor reported no significant association between the levels of education attained and LINE-1 levels [21, 27, 29, 34, 36]. None of the studies examining Alu methylation included education as a risk factor. Only one 5-mdC study included education and it reported no significant association between the levels of education attained and 5-mdC levels [1]. In summary, of the seven studies with data on education and estimates of global DNA methylation no relationship was reported for any of the seven studies.

\subsection{Lifestyle Factors}

3.2.1. Physical Activity. Five studies have investigated the association between physical activity and LINE-1 levels
(Table 3). Four studies found no significant difference between physical activity and LINE-1 levels [24, 34, 37, 50] whereas one study reported that higher physical activity was associated with higher DNA methylation levels [49]. No studies examined the association between physical activity and $A l u$ or 5-mdC. In summary, of the five studies with data on physical activity and estimates of global DNA methylation no relationship was reported for four of the studies and a positive relationship was found in one study.

3.2.2. Alcohol. As shown in Table 3, thirteen studies examined LINE-1 methylation and alcohol consumption. None of the thirteen studies reported a significant relationship between alcohol and LINE-1 levels [11, 21, 27-29, 32-34, $36-38,47]$. Three studies found no significant association between alcohol and Alu methylation [38, 40, 41]. Additionally, of the only study that examined 5-mdC and alcohol consumption, there was no significant association between alcohol and 5-mdC levels [1]. In summary, of the 17 studies with data on alcohol and estimates of global DNA methylation no relationship was reported for any of the 17 studies.

3.2.3. Smoking. As shown in Table 3, sixteen studies examined the relationship between LINE-1 and smoking and all but one of the studies reported no significant association between LINE-1 level and smoking habits [11, 21, 26-30, 32-36, 38, 47]. All four studies examining $A l u$ found no association between smoking and Alu levels [38, 40-42], and both studies involving 5-mdC found no significant association between smoking and 5 -mdC levels $[1,44]$. In summary, of the 22 studies with data on smoking and estimates of global DNA methylation no relationship was reported for 


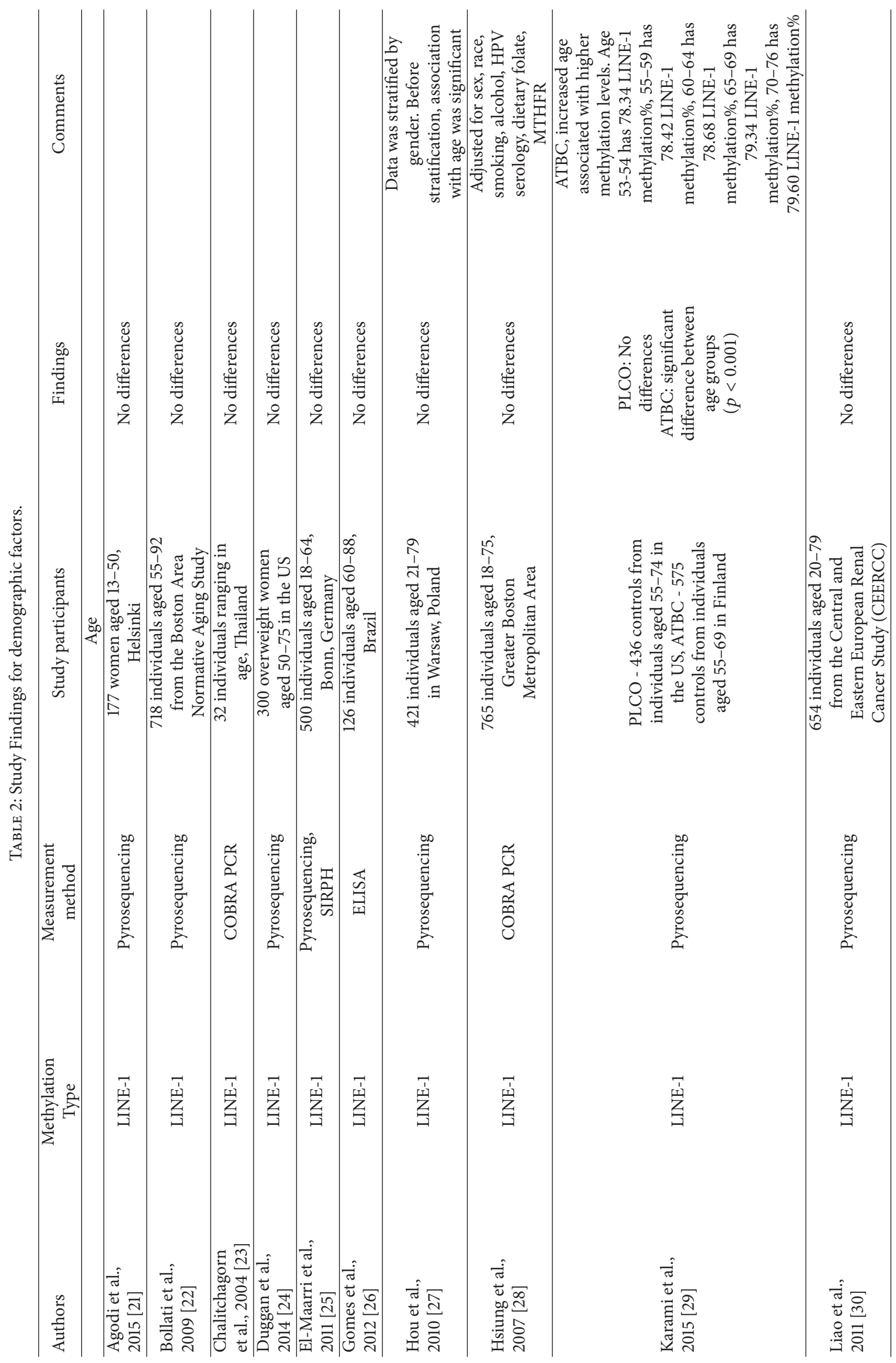




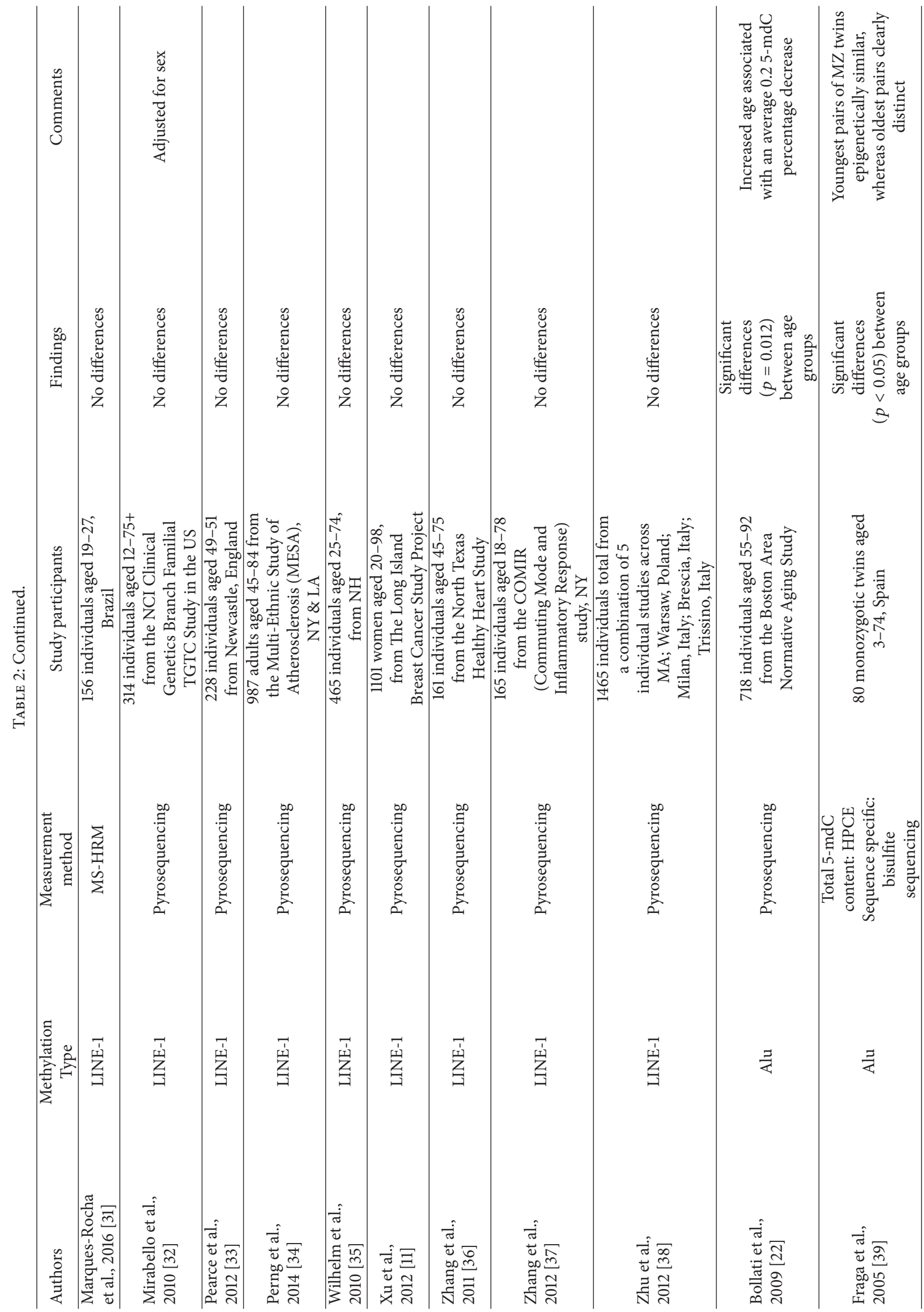




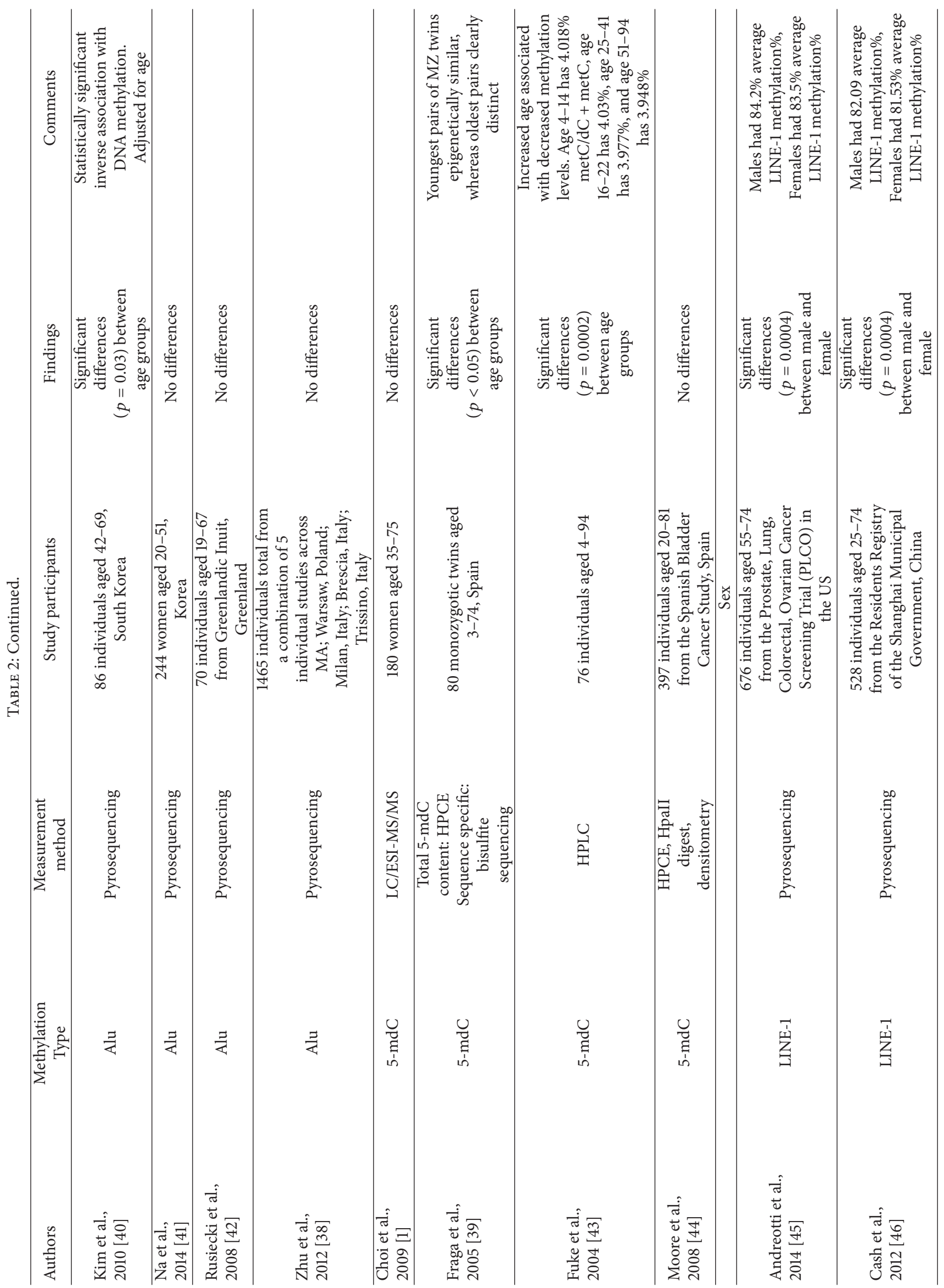




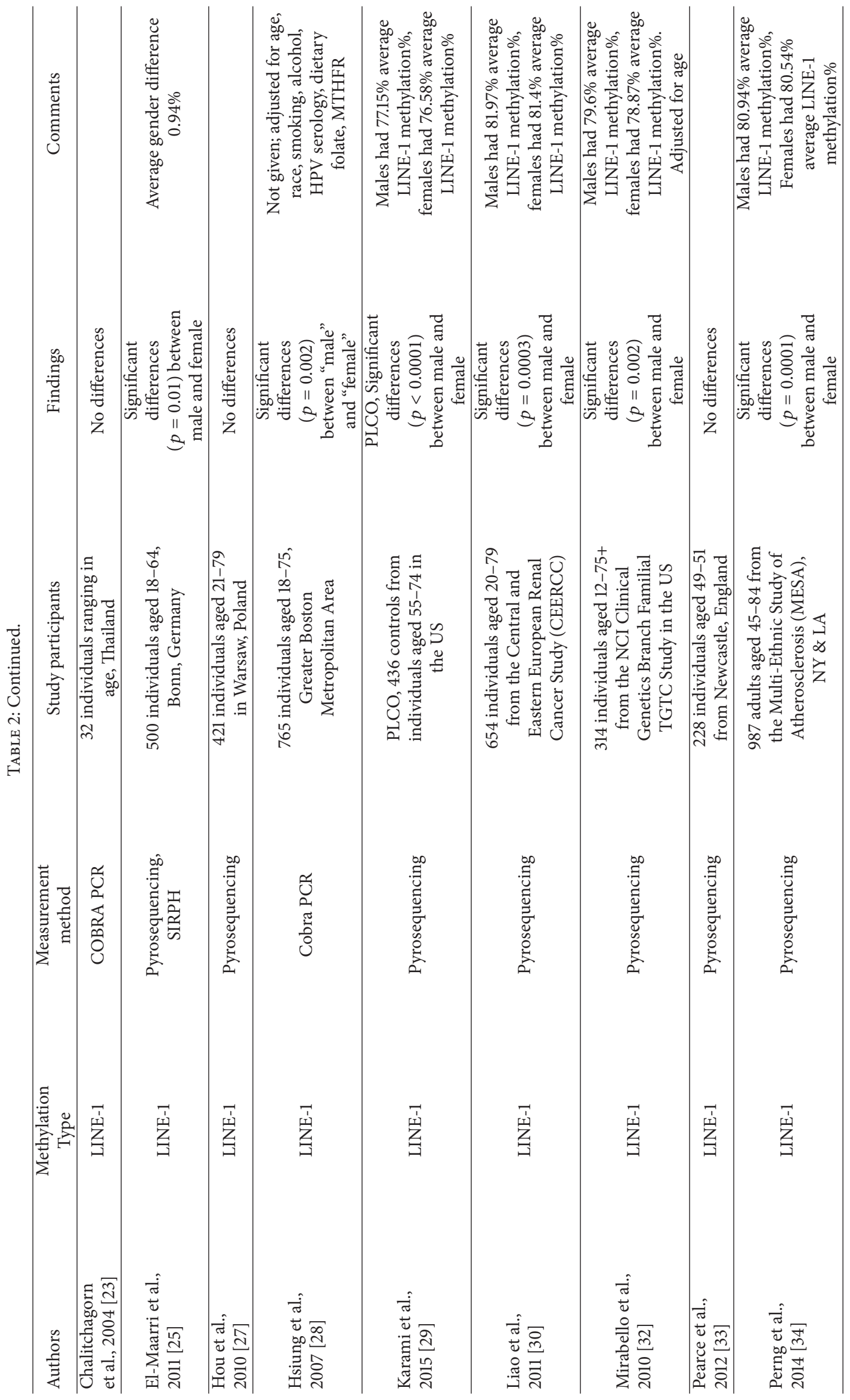




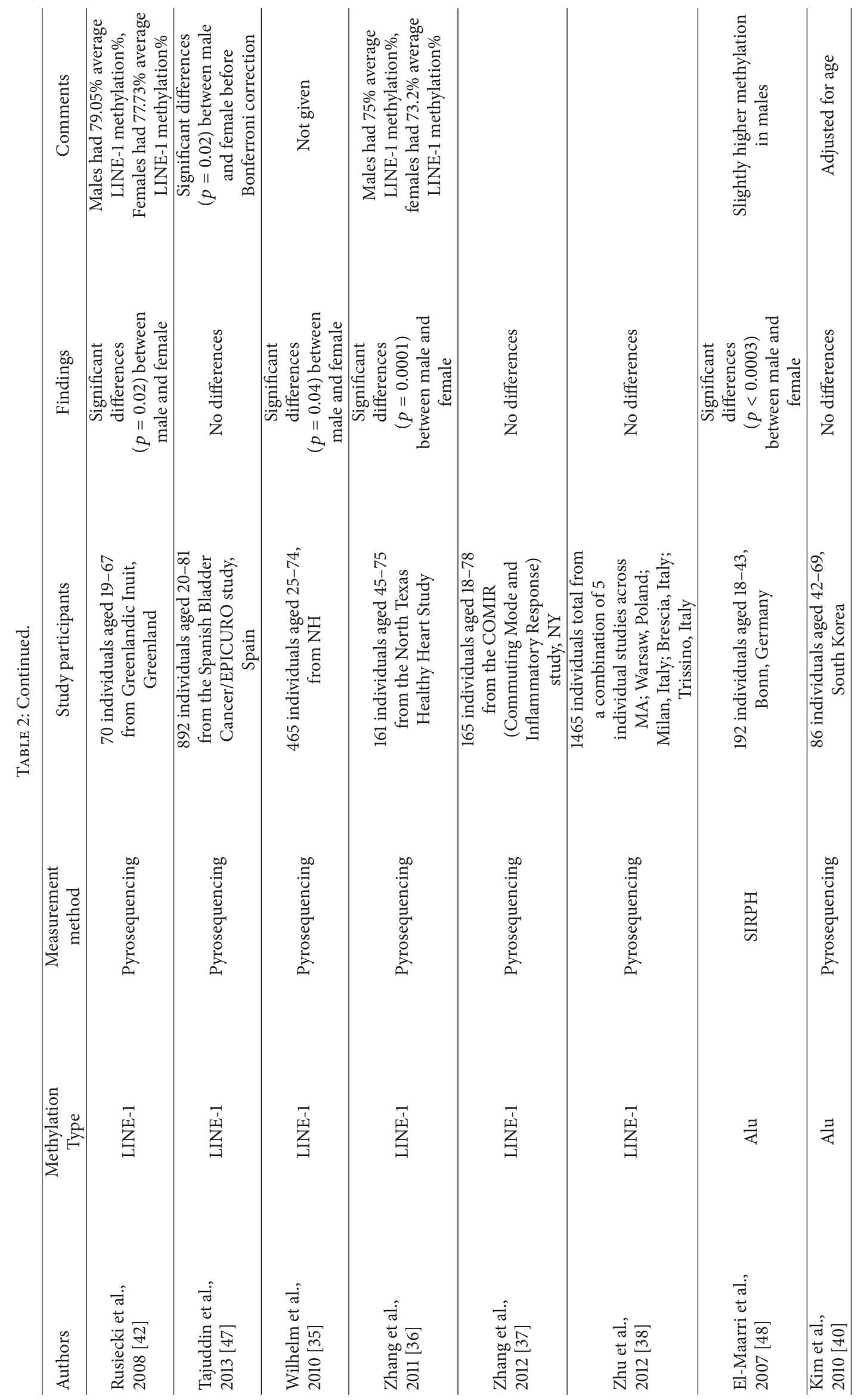




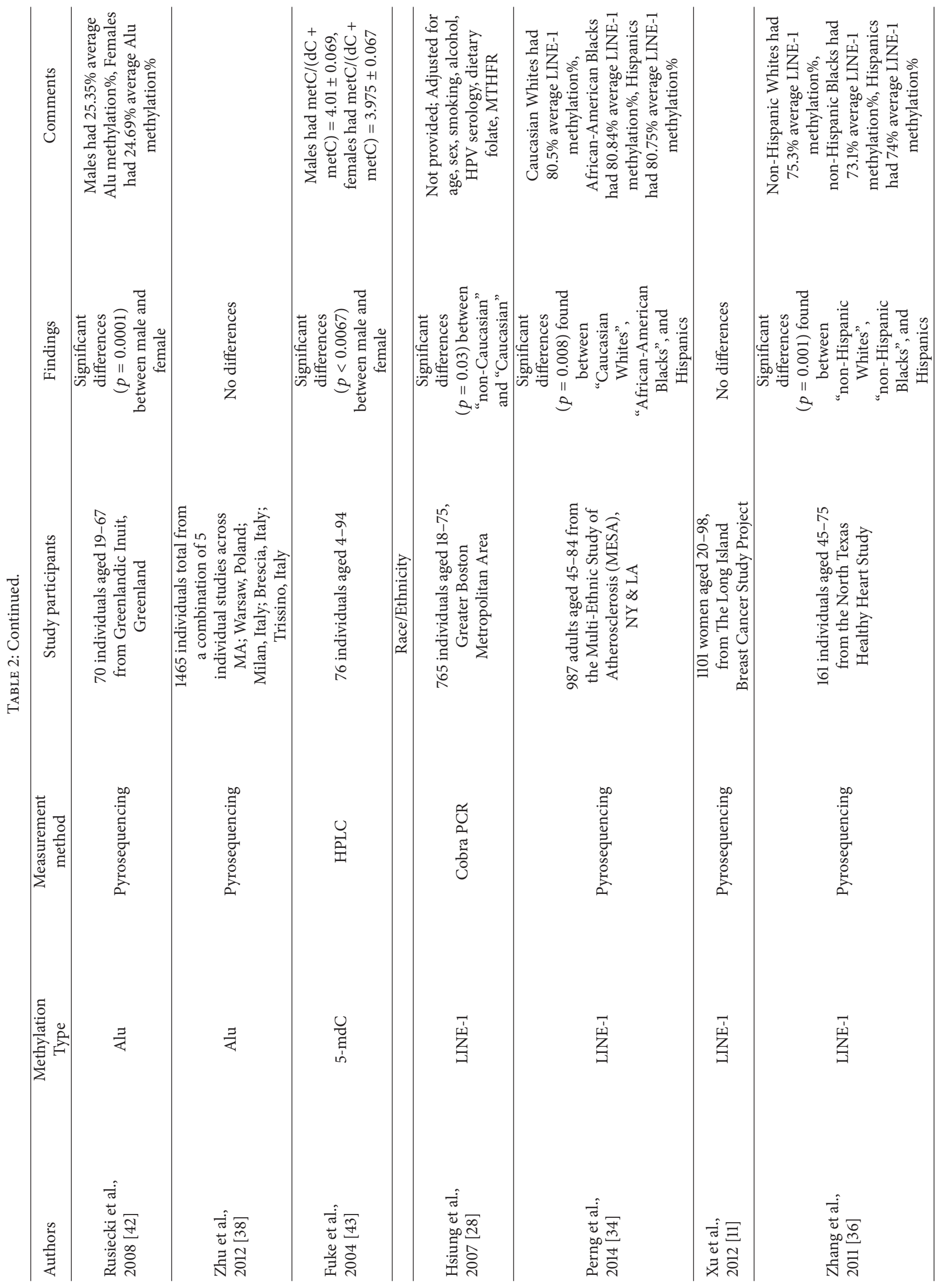




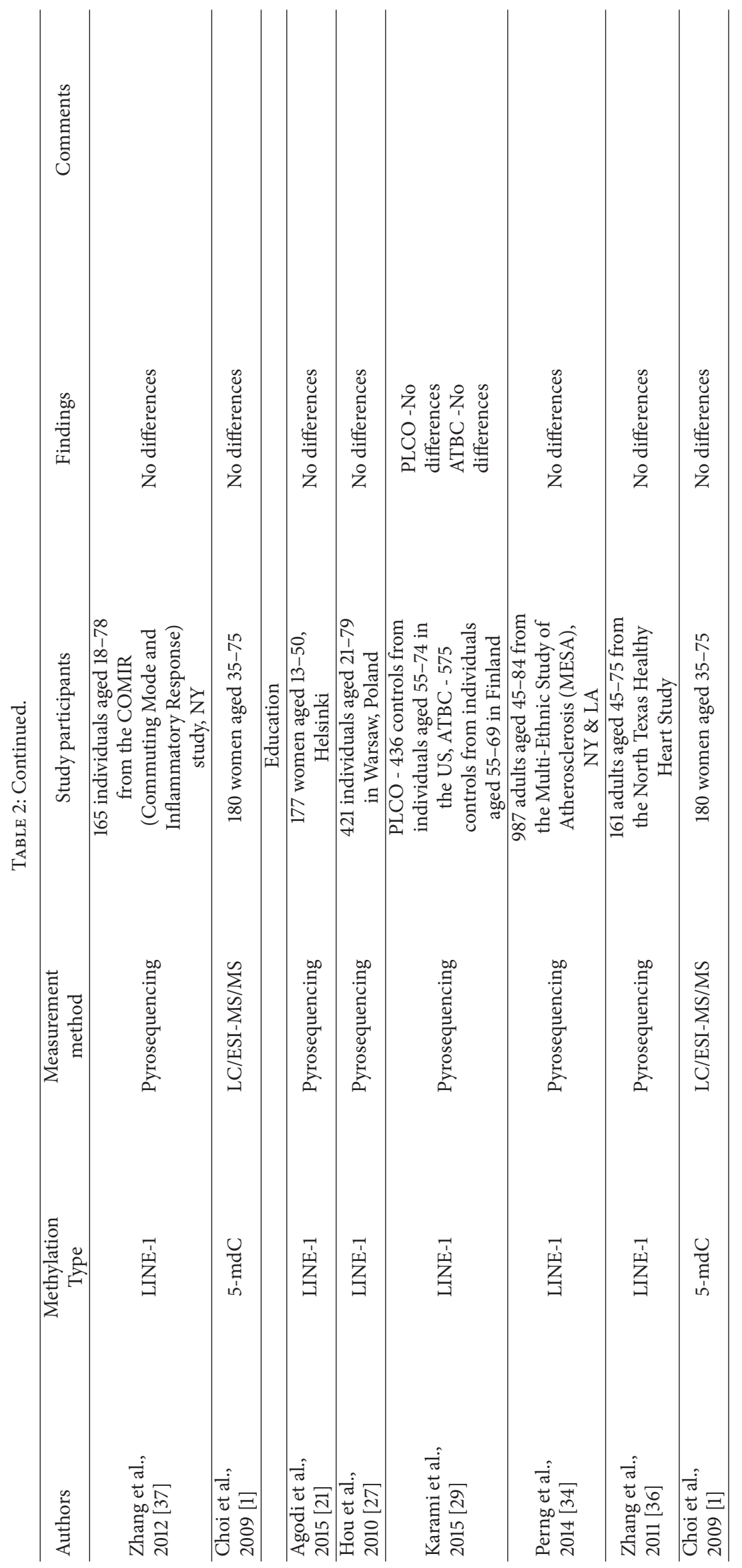




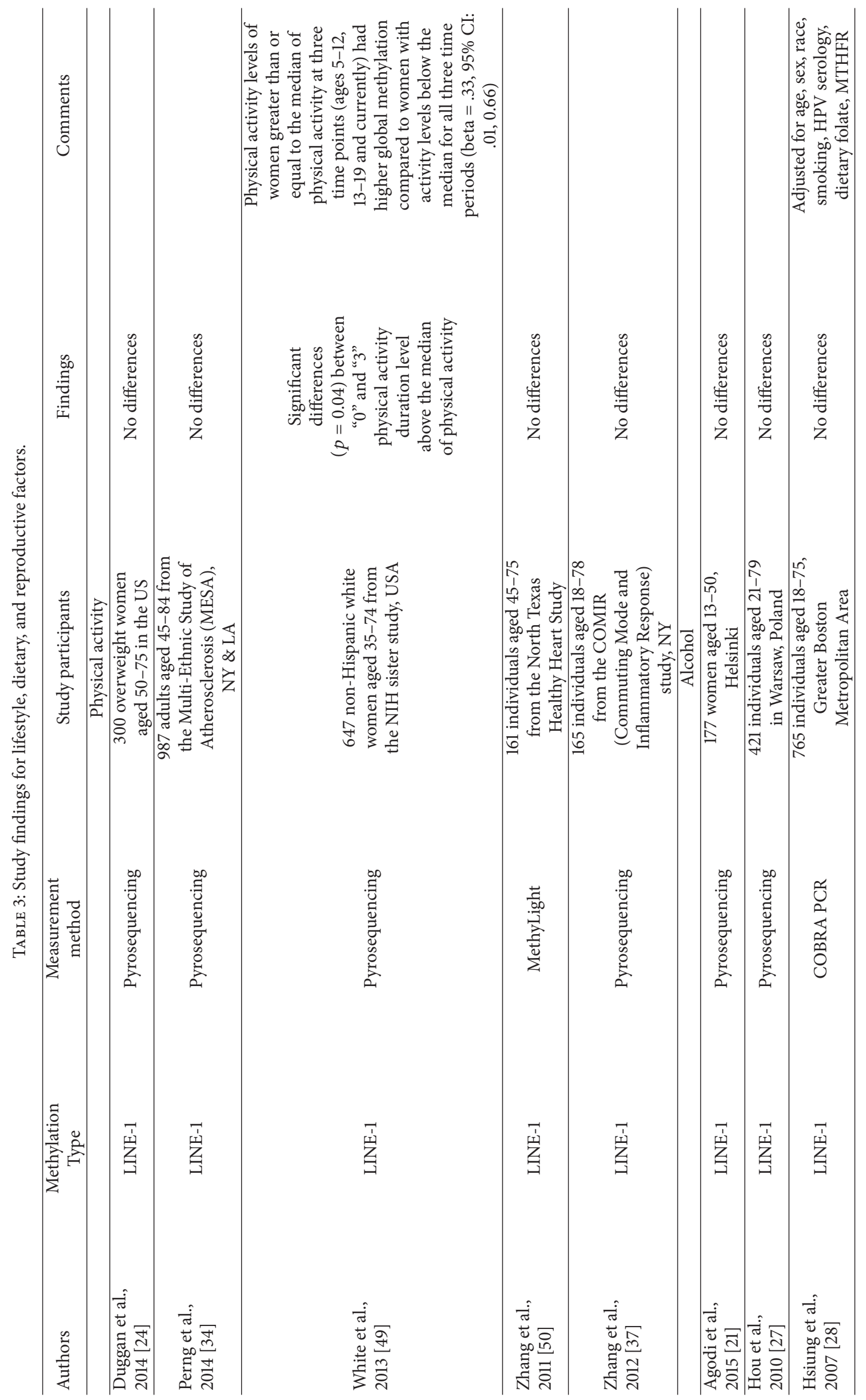




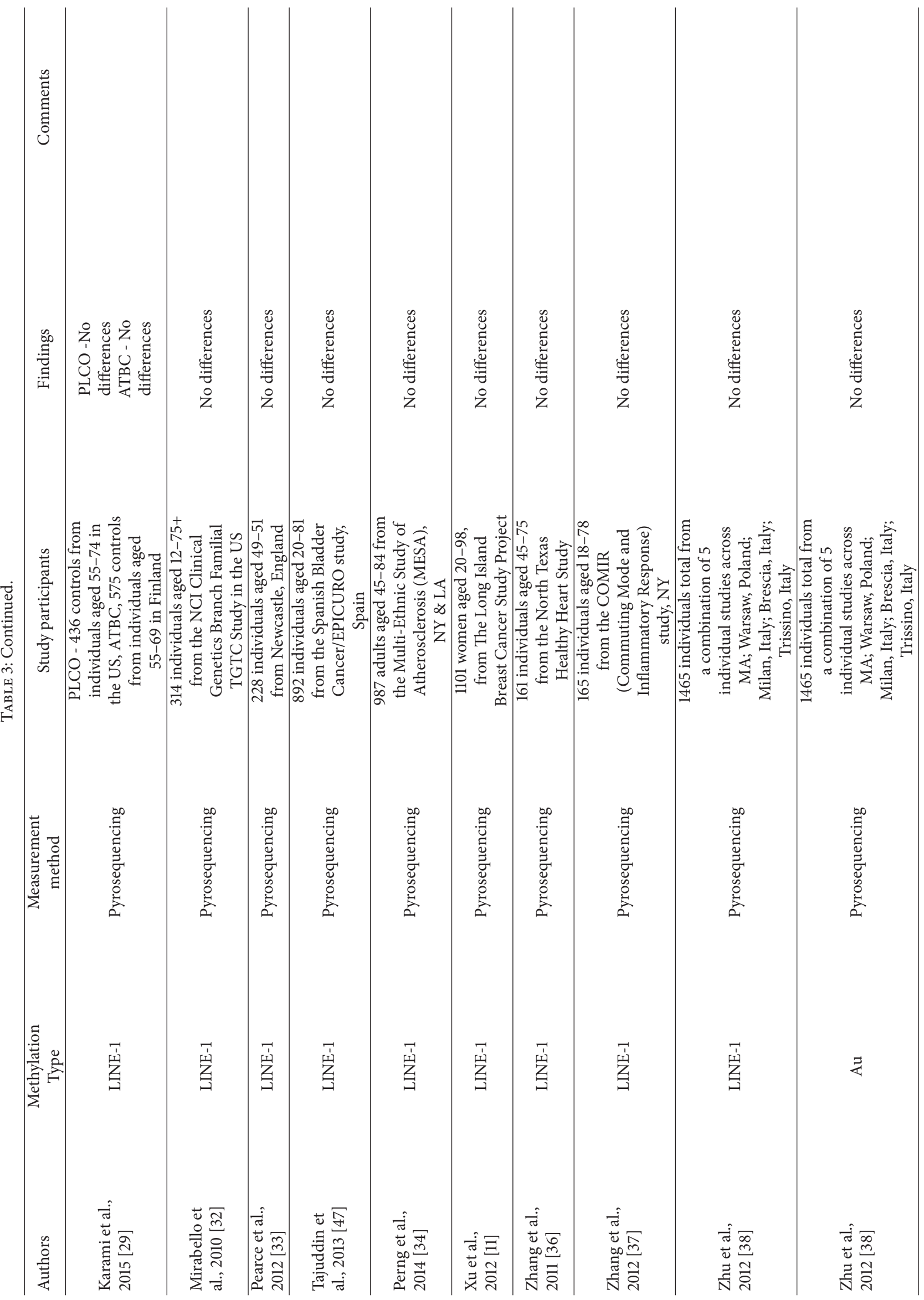




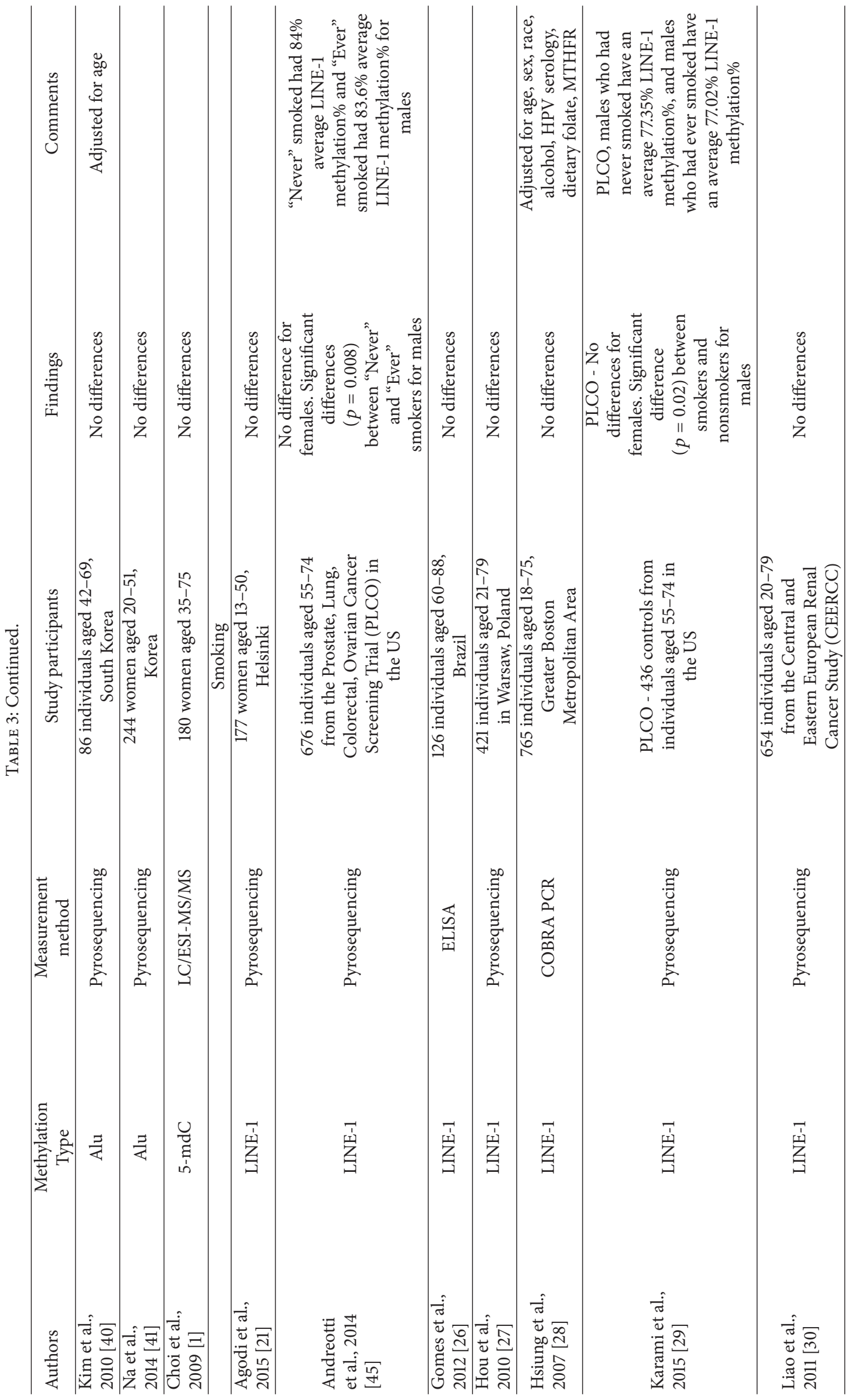




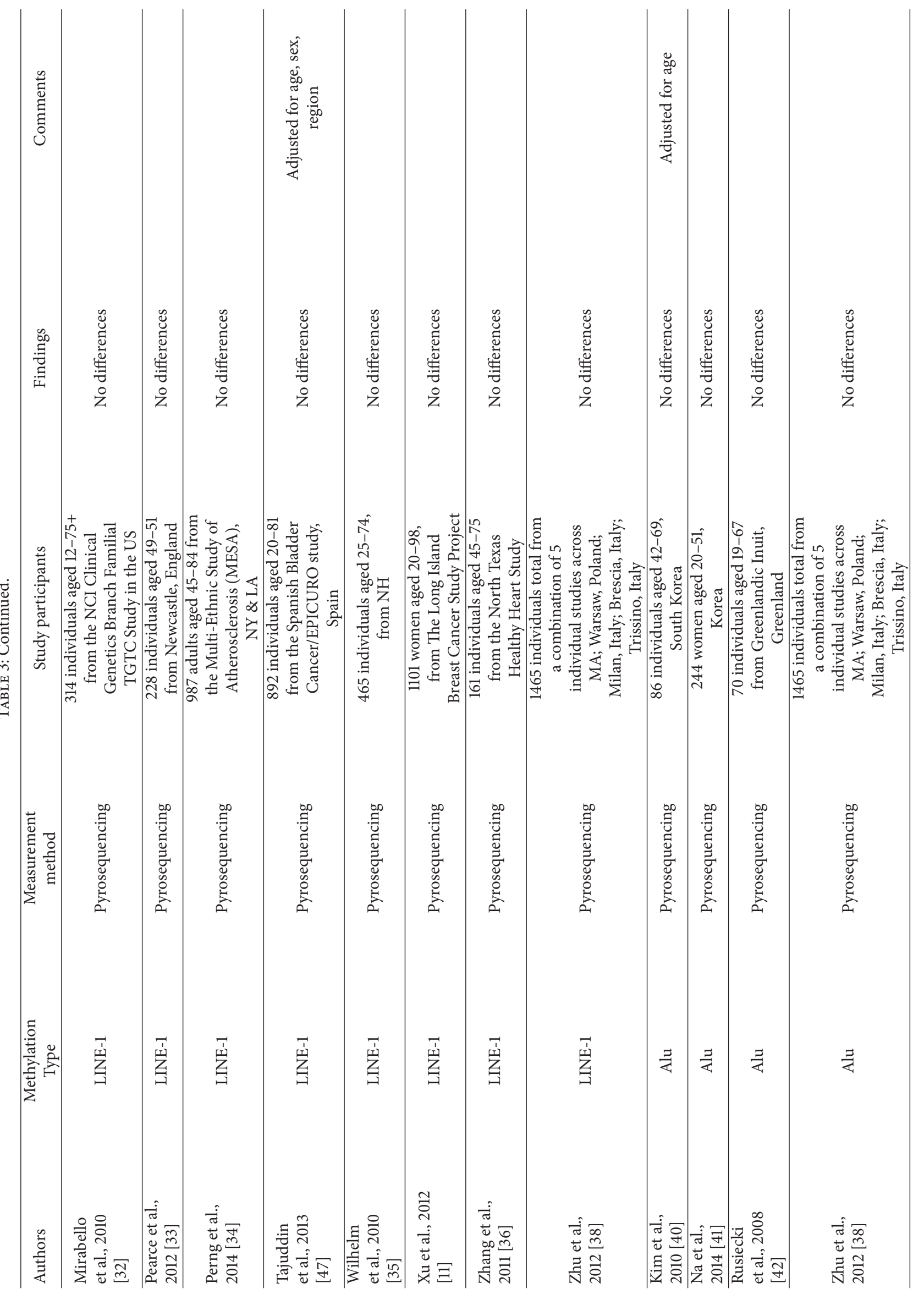




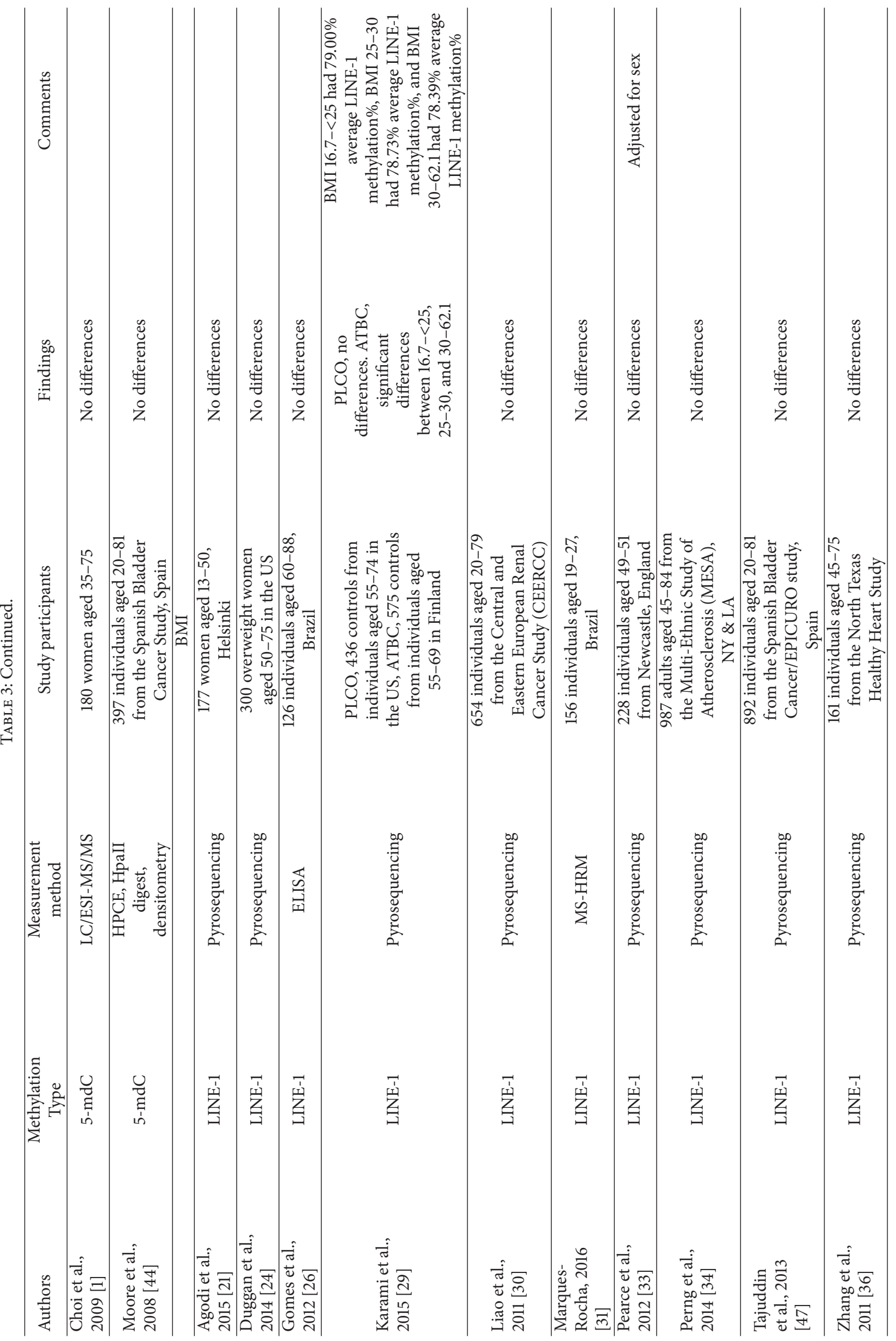




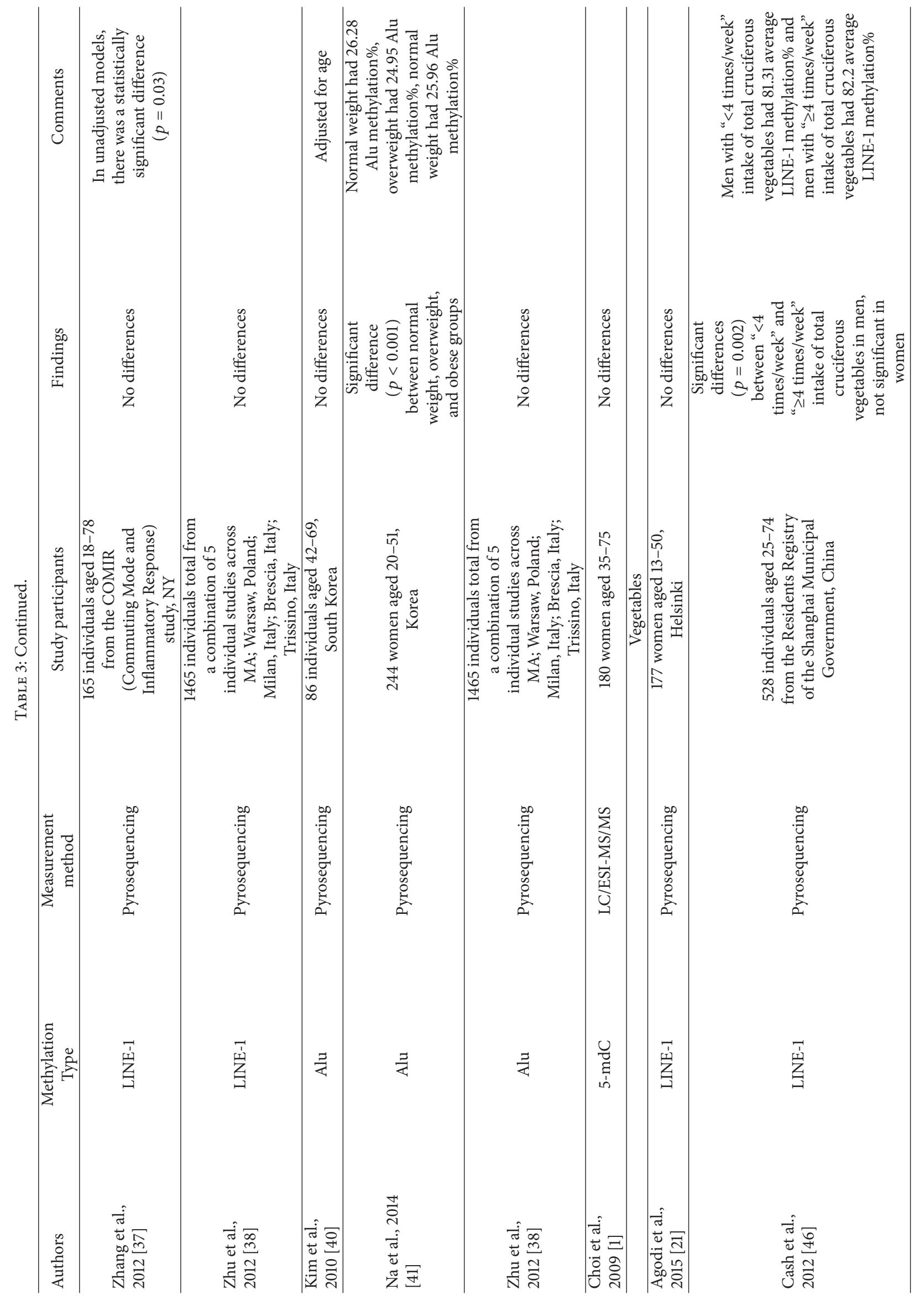




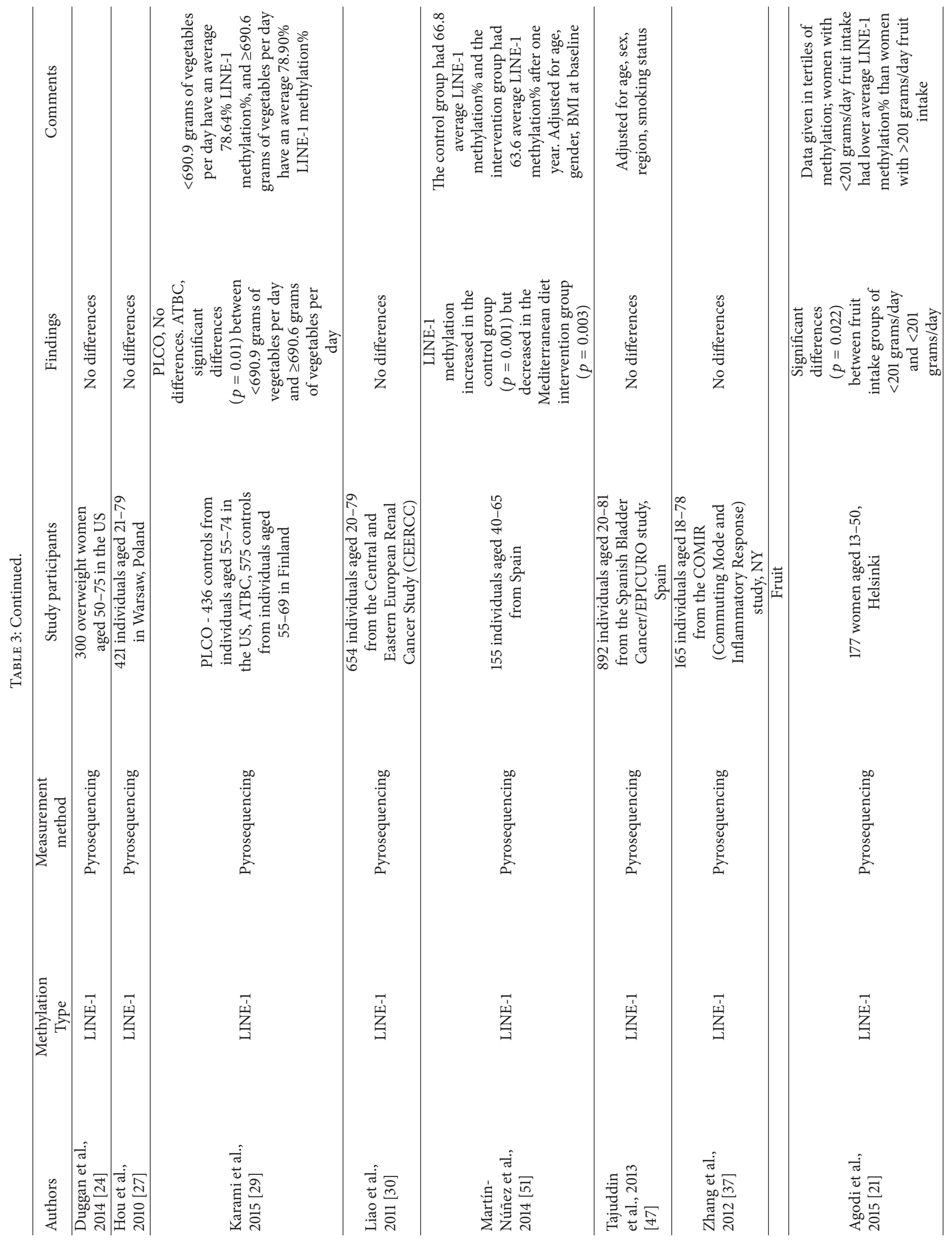




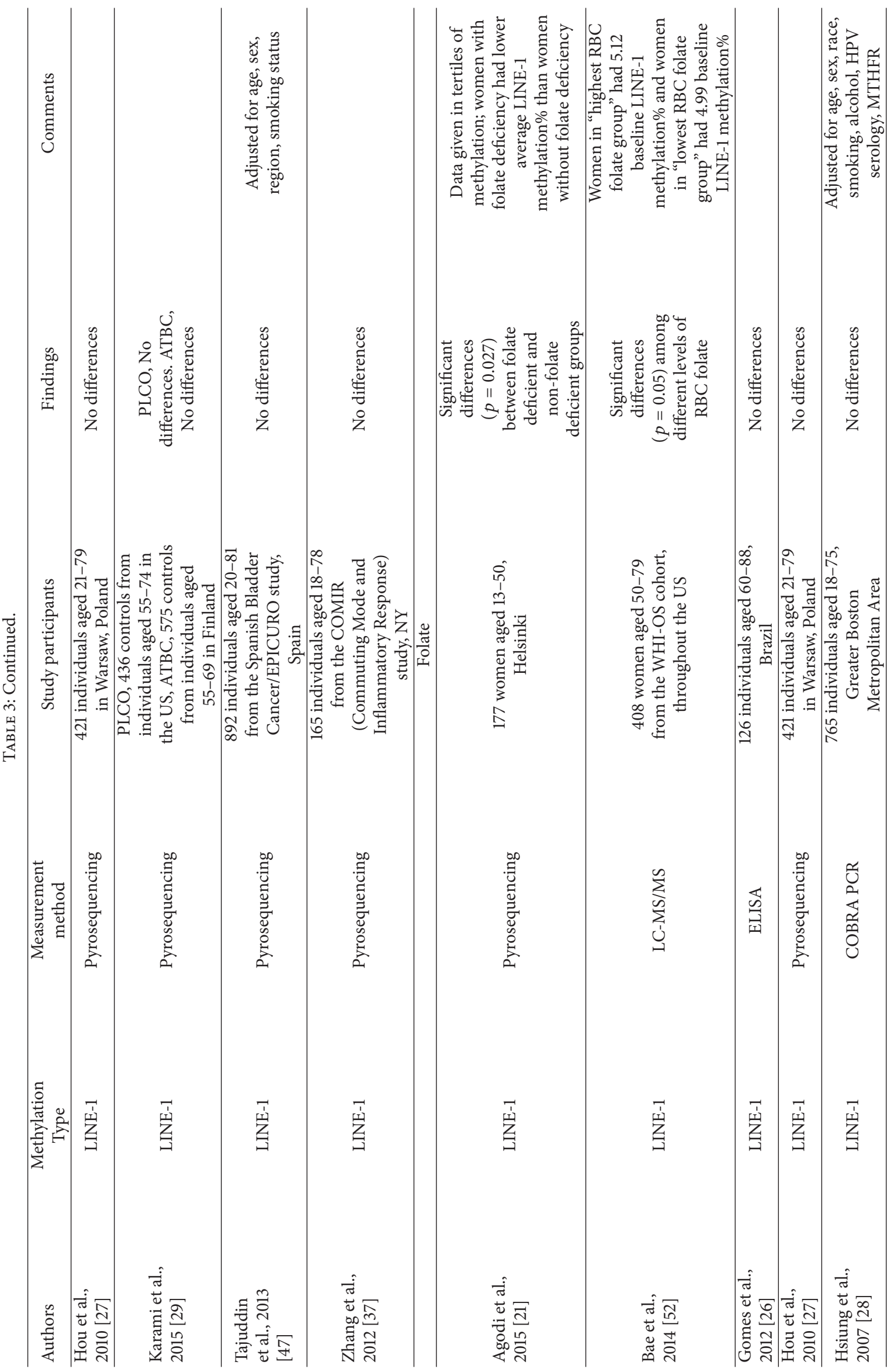




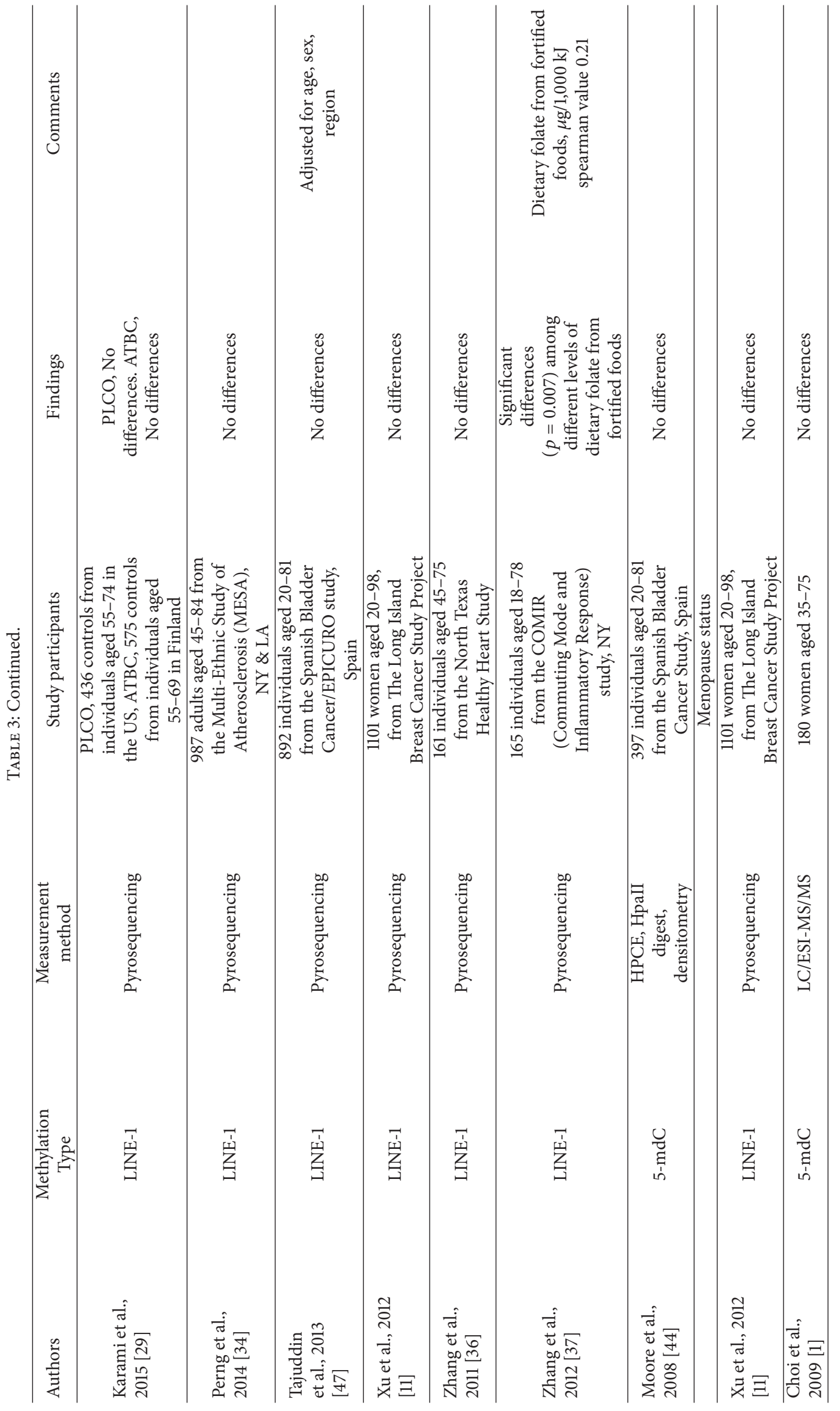




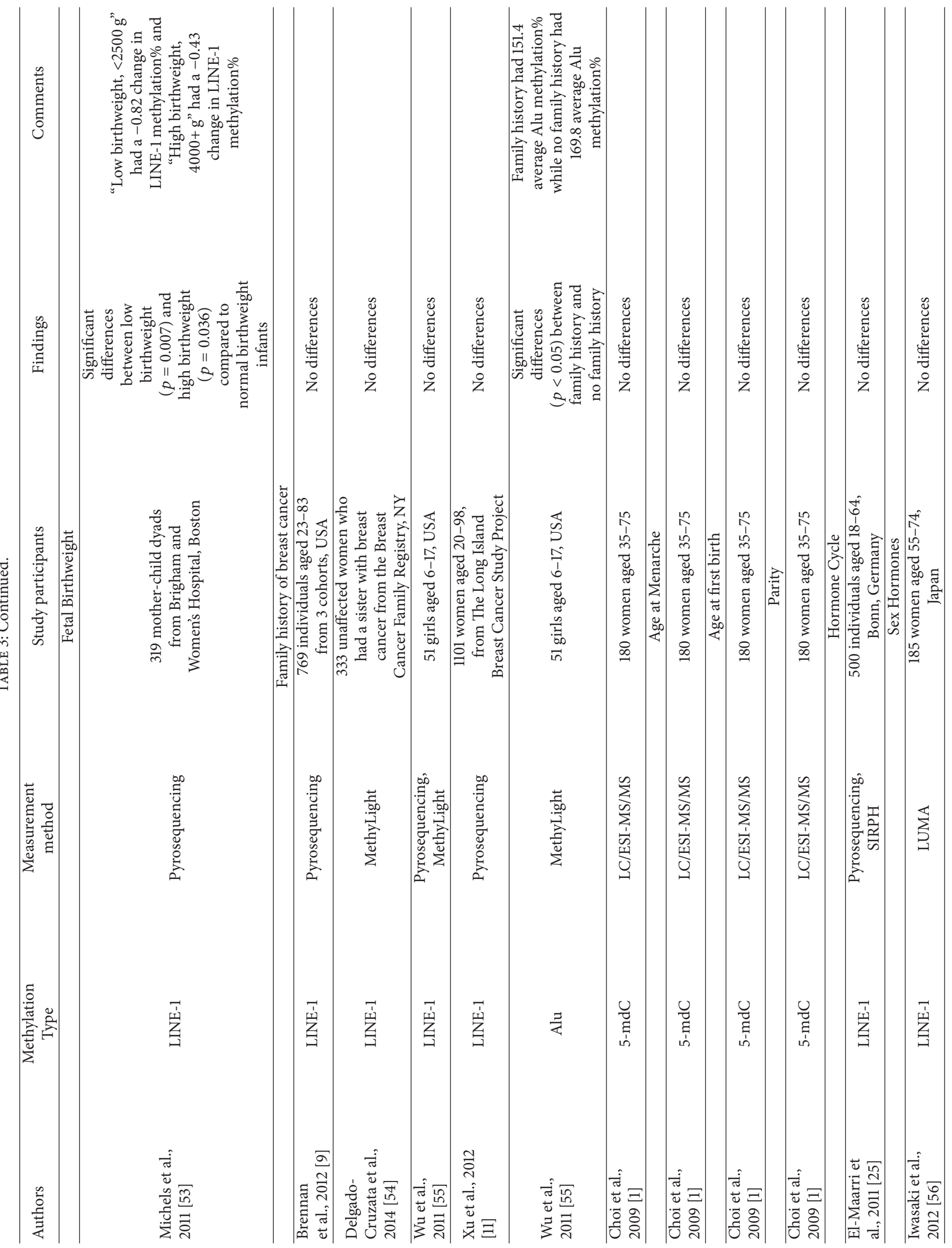




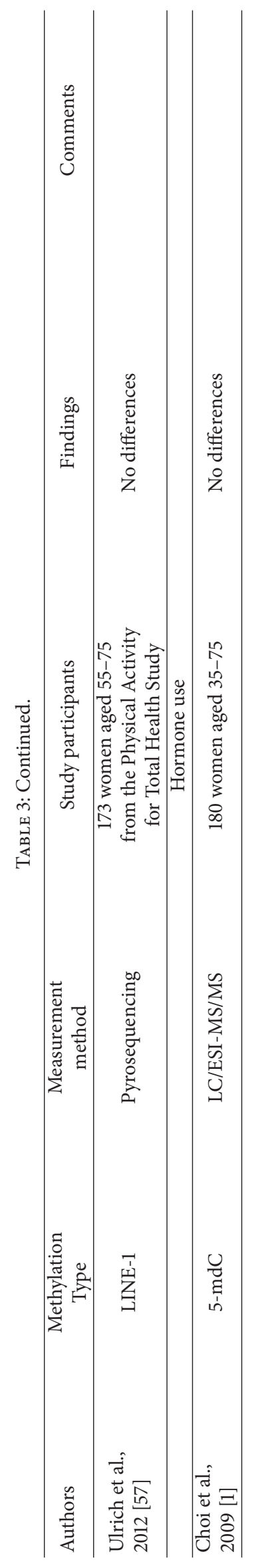


21 of the studies and a significant inverse relationship was reported for one study with smokers having lower DNA methylation.

\subsection{Dietary Factors}

3.3.1. BMI. A total of thirteen studies have examined the relationship between BMI and LINE-1 levels (Table 3). Twelve studies reported no relationship [21, 24, 26, 29-31, 33, 34, 36-38, 47] while one study found that a higher BMI was statistically significantly associated with a lower LINE-1 level [29]. Two studies found no significant association between BMI and Alu methylation [38,40] while one study found that a higher BMI was significantly associated with a lower Alu methylation level [41]. One study found no relationship between BMI and 5-mdC levels [1]. In summary, of the 17 studies with data on BMI and estimates of global DNA methylation no relationship was reported for 15 of the studies, and significant inverse relationship was reported for two studies.

3.3.2. Vegetables. As shown in Table 3, eight studies conducted found no relationship between vegetable intake and LINE-1 levels [21, 24, 27, 29, 30, 37, 47]. Two other studies showed a significant association between lower vegetable intake and lower LINE-1 methylation [29, 46]. One study found a significant association between higher adherence to a Mediterranean diet and lower LINE-1 levels [51]. In summary, of the 11 studies with data on vegetables and estimates of global DNA methylation no relationship was reported for eight of the studies, and significant positive relationship was reported for three studies.

3.3.3. Fruit. Six studies investigated the relationship between fruit intake and global white blood cell DNA methylation levels (Table 3). Five studies found no significant association between levels of fruit intake and LINE-1 levels [27, 29, 37, 47]. One study found that, in women, there was a significant association between lower fruit intake and lower LINE-1 levels [21]. In summary, of the six studies with data on fruit and estimates of global DNA methylation no relationship was reported for five of the studies, and significant positive relationship was reported for one study in women.

3.3.4. Folate. As shown in Table 3 , ten studies reported no significant relationship between dietary folate intake and LINE-1 levels [11, 26-29, 34, 36, 44, 47]. Two studies reported a statistically significant positive correlation between higher blood folate levels and higher LINE-1 levels [37, 52]. However, in one of the same studies, folate intake from natural foods and total dietary folate equivalents were not found to be associated with higher LINE-1 levels [37]. Another study reported that women with a folate deficiency had a statistically significantly lower LINE-1 level [21]. In summary, of the 13 studies with data on folate and global DNA methylation estimates no relationship was reported for ten of the studies and a significant positive relationship was reported for three of the studies.

\subsection{Health History and Reproductive Factors}

3.4.1. Menopause Status. As shown in Table 3, one study examined the relationship between menopausal status and LINE-1 methylation and did not find a significant association [11]. Another study did not find a significant association between menopausal status and 5-mdC levels [1].

3.4.2. Fetal Birthweight. A cross-sectional study investigated the relationship between fetal birthweight and LINE-1 levels and found a significant association between low $(<2500 \mathrm{~g})$ or high $(4000+\mathrm{g})$ birthweight and lower LINE-1 levels of the newborn [53] (Table 3).

3.4.3. Family History of Breast Cancer. Four studies reported no relationship between family history of breast cancer and LINE-1 levels [9, 11, 54, 55] (Table 3). Family history of breast cancer was unrelated to 5-mdC levels in another study [1]. However, one study did find a relationship between family history of breast cancer and lower Alu levels [55]. In summary, of the six studies with data on family history and estimates of global DNA methylation no relationship was reported for five of the studies, and significant inverse relationship was reported for one study.

3.4.4. Age at Menarche. One study found no association between the age at menarche and 5-mdC level [1] (Table 3).

3.4.5. Age at First Birth/Parity. As seen in Table 3, one study did not find a significant association between the age at first live birth or parity, and 5-mdC level [1].

3.4.6. Endogenous Hormones/Hormone Use. All four studies found no statistically significant association between LINE1 levels and sex hormone levels $[56,57]$ or between LINE1 levels and phase of the menstrual cycle [25] (Table 3). The only study that evaluated 5-mdC levels did not find a significant association between 5-mdC and hormone use [1].

\section{Discussion}

There was reasonably consistent evidence across studies that males have higher levels of global methylation in WBC DNA than females. There was little evidence across studies that age was associated with global methylation in WBC DNA but the populations studied were generally restricted to older adults. Age has been reported to be associated with WBC DNA LINE-1 methylation in a study that evaluated epigenetic changes throughout the lifetime of monozygotic twins [39]. None of the other demographic, lifestyle, dietary, or other risk factors were consistently associated with global WBC DNA methylation.

There are several factors that warrant consideration in interpreting the existing data on the associations between WBC DNA methylation and breast cancer risk factors. Nearly all the published studies used a composite of DNA from different subtypes of WBCs. As previously noted by others $[18,58]$, DNA methylation can vary by WBC subtype and 
the distribution of WBC subtypes varies among individuals, which could possibly obscure associations. In addition, the type and method of assessing WBC DNA methylation differed across studies, which could potentially contribute to variation in results across studies. Another possible explanation for the general lack of association with breast cancer risk factors is that the assays used may not be optimal. However, the fact that global WBC DNA methylation levels appear to be slightly lower among women than men when measured by any of the three assays tends to suggest that laboratory measurement error is not the entire explanation. Finally, studies are generally cross-sectional in design [18], and for some of the risk factors examined the number of studies was quite limited. Overall, however, it seems unlikely that these considerations account for the consistently null findings observed.

4.1. Conclusion. In summary, with the exception of sex, there is very little evidence that the wide range of breast cancer risk factors we examined (demographic, lifestyle, dietary, and health conditions) were associated with global WBC DNA methylation markers including LINE-1, 5-mdC, and Alu. Although the possibility that global DNA methylation reflects a novel breast cancer risk factor cannot be ruled out on the basis of these findings, a plausible implication of the observed lack of association between global WBC DNA methylation and most known or suspected breast cancer risk factors is that the association between global WBC DNA methylation and breast cancer, if it exists, is due to a disease effect $[16,59]$.

\section{Conflicts of Interest}

The authors declare that there are no conflicts of interest regarding the publication of this paper.

\section{Acknowledgments}

Research reported in this publication was supported in part by the National Cancer Institute of the National Institutes of Health under Award no. R15CA170111.

\section{References}

[1] J.-Y. Choi, S. R. James, P. A. Link et al., "Association between global DNA hypomethylation in leukocytes and risk of breast cancer," Carcinogenesis, vol. 30, no. 11, pp. 1889-1897, 2009.

[2] D. J. Weisenberger, M. Campan, T. I. Long et al., "Analysis of repetitive element DNA methylation by MethyLight," Nucleic Acids Research, vol. 33, no. 21, pp. 6823-6836, 2005.

[3] J. Soares, A. E. Pinto, C. V. Cunha et al., "Global DNA hypomethylation in breast carcinoma: correlation with prognostic factors and tumor progression," Cancer, vol. 85, no. 1, pp. $112-118,1999$.

[4] J. Bernardino, C. Roux, A. Almeida et al., "DNA hypomethylation in breast cancer: an independent parameter of tumor progression?" Cancer Genetics and Cytogenetics, vol. 97, no. 2, pp. 83-89, 1997.
[5] M. A. Gama-Sosa, V. A. Slagel, R. W. Trewyn et al., "The 5methylcytosine content of DNA from human tumors," Nucleic Acids Research, vol. 11, no. 19, pp. 6883-6894, 1983.

[6] K. Jackson, M. C. Yu, K. Arakawa et al., "DNA hypomethylation is prevalent even in low-grade breast cancers," Cancer Biology and Therapy, vol. 3, no. 12, pp. 1225-1231, 2004.

[7] M. Esteller, M. F. Fraga, M. Guo et al., "DNA methylation patterns in hereditary human cancers mimic sporadic tumorigenesis," Human Molecular Genetics, vol. 10, no. 26, pp. 30013007, 2001.

[8] L. A. DeRoo, S. C. E. Bolick, Z. Xu et al., "Global DNA methylation and one-carbon metabolism gene polymorphisms and the risk of breast cancer in the Sister Study," Carcinogenesis, vol. 35, no. 2, pp. 333-338, 2014.

[9] K. Brennan, M. Garcia-Closas, N. Orr et al., "Intragenic ATM methylation in peripheral blood DNA as a biomarker of breast cancer risk," Cancer Research, vol. 72, no. 9, pp. 2304-2313, 2012.

[10] H.-C. Wu, Q. Wang, H.-I. Yang, W.-Y. Tsai, C.-J. Chen, and R. M. Santella, "Global dna methylation levels in white blood cells as a biomarker for hepatocellular carcinoma risk: a nested casecontrol study," Carcinogenesis, vol. 33, no. 7, pp. 1340-1345, 2012.

[11] X. Xu, M. D. Gammon, H. Hernandez-Vargas et al., "DNA methylation in peripheral blood measured by LUMA is associated with breast cancer in a population-based study," The FASEB Journal, vol. 26, no. 6, pp. 2657-2666, 2012.

[12] Y. H. Cho, H. Yazici, H.-C. Wu et al., "Aberrant promoter hypermethylation and genomic hypomethylation in tumor, adjacent normal tissues and blood from breast cancer patients," Anticancer Research, vol. 30, no. 7, pp. 2489-2496, 2010.

[13] M. Widschwendter, H. Fiegl, D. Egle et al., "Epigenetic stem cell signature in cancer," Nature Genetics, vol. 39, no. 2, pp. 157-158, 2007.

[14] L. Delgado-Cruzata, H.-C. Wu, M. Perrin et al., "Global DNA methylation levels in white blood cell DNA from sisters discordant for breast cancer from the New York site of the breast cancer family registry," Epigenetics, vol. 7, no. 8, pp. 868-874, 2012.

[15] A. Kuchiba, M. Iwasaki, H. Ono et al., "Global methylation levels in peripheral blood leukocyte DNA by LUMA and breast cancer: a case-control study in Japanese women," British Journal of Cancer, vol. 110, no. 11, pp. 2765-2771, 2014.

[16] Q. Tang, J. Cheng, X. Cao, H. Surowy, and B. Burwinkel, "Blood-based DNA methylation as biomarker for breast cancer: a systematic review," Clinical Epigenetics, vol. 8, no. 1, article 115, 2016.

[17] M. Garcia-Closas, F. J. Couch, S. Lindstrom et al., "Genomewide association studies identify four ER negative-specific breast cancer risk loci," Nature Genetics, vol. 45, no. 4, pp. 398e1$398 \mathrm{e} 2,2013$.

[18] M. B. Terry, L. Delgado-Cruzata, N. Vin-Raviv, H. C. Wu, and R. M. Santella, "DNA methylation in white blood cells: association with risk factors in epidemiologic studies," Epigenetics, vol. 6, no. 7, pp. 828-837, 2011.

[19] American Cancer Society, Breast Cancer Facts \& Figures 20152016, American Cancer Society, Atlanta, Ga, USA, 2015.

[20] J. D. De Batlle, P. Ferrari, V. Chajes et al., "Dietary folate intake and breast cancer risk: European prospective investigation into cancer and nutrition," Journal of the National Cancer Institute, vol. 107, no. 1, 2015.

[21] A. Agodi, M. Barchitta, A. Quattrocchi et al., "Low fruit consumption and folate deficiency are associated with LINE-1 
hypomethylation in women of a cancer-free population," Genes and Nutrition, vol. 10, no. 5, article 30, 2015.

[22] V. Bollati, J. Schwartz, R. Wright et al., "Decline in genomic DNA methylation through aging in a cohort of elderly subjects," Mechanisms of Ageing and Development, vol. 130, no. 4, pp. 234239, 2009.

[23] K. Chalitchagorn, S. Shuangshoti, N. Hourpai et al., "Distinctive pattern of LINE-1 methylation level in normal tissues and the association with carcinogenesis," Oncogene, vol. 23, no. 54, pp. 8841-8846, 2004.

[24] C. Duggan, L. Xiao, M. B. Terry, and A. McTiernan, "No effect of weight loss on LINE-1 methylation levels in peripheral blood leukocytes from postmenopausal overweight women," Obesity, vol. 22, no. 9, pp. 2091-2096, 2014.

[25] O. El-Maarri, M. Walier, F. Behne et al., "Methylation at global LINE-1 repeats in human blood are affected by gender but not by age or natural hormone cycles," PLoS ONE, vol. 6, no. 1, Article ID e16252, 2011.

[26] M. V. M. Gomes, L. V. Toffoli, D. W. Arruda et al., "Age-related changes in the global DNA methylation profile of leukocytes are linked to nutrition but are not associated with the MTHFR C677T genotype or to functional capacities," PLoS ONE, vol. 7, no. 12, Article ID e52570, 2012.

[27] L. Hou, H. Wang, S. Sartori et al., "Blood leukocyte DNA hypomethylation and gastric cancer risk in a high-risk Polish population," International Journal of Cancer, vol. 127, no. 8, pp. 1866-1874, 2010.

[28] D. T. Hsiung, C. J. Marsit, E. A. Houseman et al., "Global DNA methylation level in whole blood as a biomarker in head and neck squamous cell carcinoma," Cancer Epidemiology Biomarkers and Prevention, vol. 16, no. 1, pp. 108-114, 2007.

[29] S. Karami, G. Andreotti, L. M. Liao et al., "Line1 methylation levels in pre-diagnostic leukocyte DNA and future renal cell carcinoma risk," Epigenetics, vol. 10, no. 4, pp. 282-292, 2015.

[30] L. M. Liao, P. Brennan, D. M. van Bemmel et al., "Line-1 methylation levels in leukocyte DNA and risk of renal cell cancer," PLoS ONE, vol. 6, no. 11, Article ID e27361, 2011.

[31] J. L. Marques-Rocha, F. I. Milagro, M. L. Mansego, D. M. Mourão, J. A. Martínez, and J. Bressan, "LINE-1 methylation is positively associated with healthier lifestyle but inversely related to body fat mass in healthy young individuals," Epigenetics, vol. 11, no. 1, pp. 49-60, 2016.

[32] L. Mirabello, S. A. Savage, L. Korde, S. M. Gadalla, and M. H. Greene, "LINE-1 methylation is inherited in familial testicular cancer kindreds," BMC Medical Genetics, vol. 11, article 77, 2010.

[33] M. S. Pearce, J. C. Mcconnell, C. Potter et al., "Global LINE-1 DNA methylation is associated with blood glycaemic and lipid profiles," International Journal of Epidemiology, vol. 41, no. 1, pp. 210-217, 2012.

[34] W. Perng, E. Villamor, M. R. Shroff et al., "Dietary intake, plasma homocysteine, and repetitive element DNA methylation in the Multi-Ethnic Study of Atherosclerosis (MESA)," Nutrition, Metabolism and Cardiovascular Diseases, vol. 24, no. 6, pp. 614-622, 2014.

[35] C. S. Wilhelm, K. T. Kelsey, R. Butler et al., "Implications of LINE1 methylation for bladder cancer risk in women," Clinical Cancer Research, vol. 16, no. 5, pp. 1682-1689, 2010.

[36] F. F. Zhang, R. Cardarelli, J. Carroll et al., "Significant differences in global genomic DNA methylation by gender and race/ethnicity in peripheral blood," Epigenetics, vol. 6, no. 5, pp. 623-629, 2011.
[37] F. F. Zhang, R. M. Santella, M. Wolff, M. A. Kappil, S. B. Markowitz, and A. Morabia, "White blood cell global methylation and IL-6 promoter methylation in association with diet and lifestyle risk factors in a cancer-free population," Epigenetics, vol. 7, no. 6, pp. 606-614, 2012.

[38] Z.-Z. Zhu, L. Hou, V. Bollati et al., "Predictors of global methylation levels in blood DNA of healthy subjects: a combined analysis," International Journal of Epidemiology, vol. 41, no. 1, pp. 126-139, 2012.

[39] M. F. Fraga, E. Ballestar, M. F. Paz et al., "Epigenetic differences arise during the lifetime of monozygotic twins," Proceedings of the National Academy of Sciences of the United States of America, vol. 102, no. 30, pp. 10604-10609, 2005.

[40] K.-Y. Kim, D.-S. Kim, S.-K. Lee et al., "Association of lowdose exposure to persistent organic pollutants with global DNA hypomethylation in healthy Koreans," Environmental Health Perspectives, vol. 118, no. 3, pp. 370-374, 2010.

[41] Y. K. Na, H. S. Hong, D. H. Lee, W. K. Lee, and D. S. Kim, "Effect of body mass index on global DNA methylation in healthy Korean women," Molecules and Cells, vol. 37, no. 6, pp. 467-472, 2014.

[42] J. A. Rusiecki, A. Baccarelli, V. Bollati, L. Tarantini, L. E. Moore, and E. C. Bonefeld-Jorgensen, "Global DNA hypomethylation is associated with high serum-persistent organic pollutants in Greenlandic inuit," Environmental Health Perspectives, vol. 116, no. 11, pp. 1547-1552, 2008.

[43] C. Fuke, M. Shimabukuro, A. Petronis et al., "Age related changes in 5-methylcytosine content in human peripheral leukocytes and placentas: An HPLC-based study," Annals of Human Genetics, vol. 68, no. 3, pp. 196-204, 2004.

[44] L. E. Moore, R. M. Pfeiffer, C. Poscablo et al., "Genomic DNA hypomethylation as a biomarker for bladder cancer susceptibility in the Spanish bladder cancer study: a case-control study," The Lancet Oncology, vol. 9, no. 4, pp. 359-366, 2008.

[45] G. Andreotti, S. Karami, R. M. Pfeiffer et al., "LINE1 methylation levels associated with increased bladder cancer risk in prediagnostic blood DNA among US (PLCO) and European (ATBC) cohort study participants," Epigenetics, vol. 9, no. 3, pp. 404-415, 2014.

[46] H. L. Cash, L. Tao, J.-M. Yuan et al., "LINE-1 hypomethylation is associated with bladder cancer risk among nonsmoking Chinese," International Journal of Cancer, vol. 130, no. 5, pp. 1151-1159, 2012.

[47] S. M. Tajuddin, A. F. S. Amaral, A. F. Fernández et al., "Genetic and non-genetic predictors of LINE-1 methylation in leukocyte DNA," Environmental Health Perspectives, vol. 121, no. 6, pp. 650-656, 2013.

[48] O. El-Maarri, T. Becker, J. Junen et al., "Gender specific differences in levels of DNA methylation at selected loci from human total blood: a tendency toward higher methylation levels in males," Human Genetics, vol. 122, no. 5, pp. 505-514, 2007.

[49] A. J. White, D. P. Sandler, S. C. E. Bolick, Z. Xu, J. A. Taylor, and L. A. Deroo, "Recreational and household physical activity at different time points and DNA global methylation," European Journal of Cancer, vol. 49, no. 9, pp. 2199-2206, 2013.

[50] F. F. Zhang, R. Cardarelli, J. Carroll et al., "Physical activity and global genomic DNA methylation in a cancer-free population," Epigenetics, vol. 6, no. 3, pp. 293-299, 2011.

[51] G. M. Martín-Núñez, R. Cabrera-Mulero, E. Rubio-Martín et al., "Methylation levels of the SCD1 gene promoter and LINE-1 repeat region are associated with weight change: an intervention 
study," Molecular Nutrition and Food Research, vol. 58, no. 7, pp. 1528-1536, 2014.

[52] S. Bae, C. M. Ulrich, L. B. Bailey et al., "Impact of folic acid fortification on global DNA methylation and one-carbon biomarkers in the Women's Health Initiative Observational Study cohort," Epigenetics, vol. 9, no. 3, pp. 396-403, 2014.

[53] K. B. Michels, H. R. Harris, and L. Barault, "Birthweight, maternal weight trajectories and global DNA methylation of LINE-1 repetitive elements," PLoS ONE, vol. 6, no. 9, Article ID e25254, 2011.

[54] L. Delgado-Cruzata, H.-C. Wu, Y. Liao, R. M. Santella, and M. B. Terry, "Differences in DNA methylation by extent of breast cancer family history in unaffected women," Epigenetics, vol. 9, no. 2, pp. 243-248, 2014.

[55] H.-C. Wu, E. M. John, J. S. Ferris et al., "Global DNA methylation levels in girls with and without a family history of breast cancer," Epigenetics, vol. 6, no. 1, pp. 29-33, 2011.

[56] M. Iwasaki, H. Ono, A. Kuchiba et al., "Association of postmenopausal endogenous sex hormones with global methylation level of leukocyte DNA among Japanese women," BMC Cancer, vol. 12, article 323, 2012.

[57] C. M. Ulrich, A. T. Toriola, L. M. Koepl et al., "Metabolic, hormonal and immunological associations with global DNA methylation among postmenopausal women," Epigenetics, vol. 7, no. 9, pp. 1020-1028, 2012.

[58] H.-C. Wu, L. Delgado-Cruzata, J. D. Flom et al., "Global methylation profles in DNA from different blood cell types," Epigenetics, vol. 6, no. 1, pp. 76-85, 2011.

[59] M. García-Closas, M. H. Gail, K. T. Kelsey, and R. G. Ziegler, "Searching for blood DNA methylation markers of breast cancer risk and early detection," Journal of the National Cancer Institute, vol. 105, no. 10, pp. 678-680, 2013. 


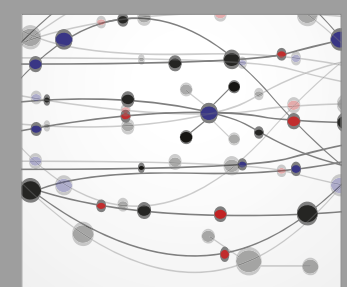

The Scientific World Journal
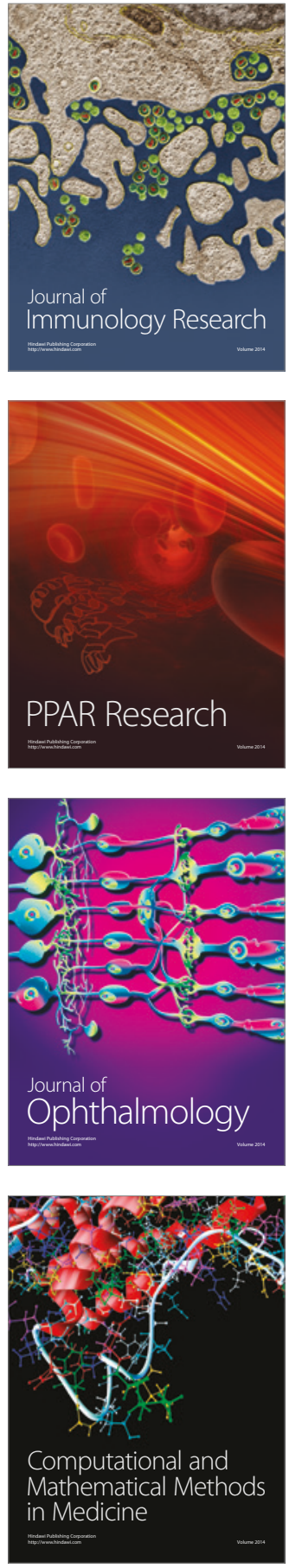

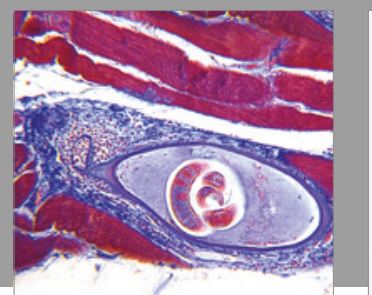

Gastroenterology Research and Practice
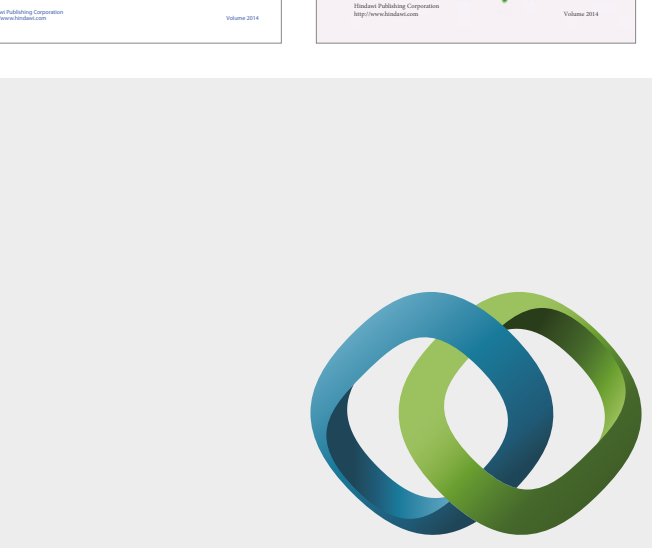

\section{Hindawi}

Submit your manuscripts at

https://www.hindawi.com
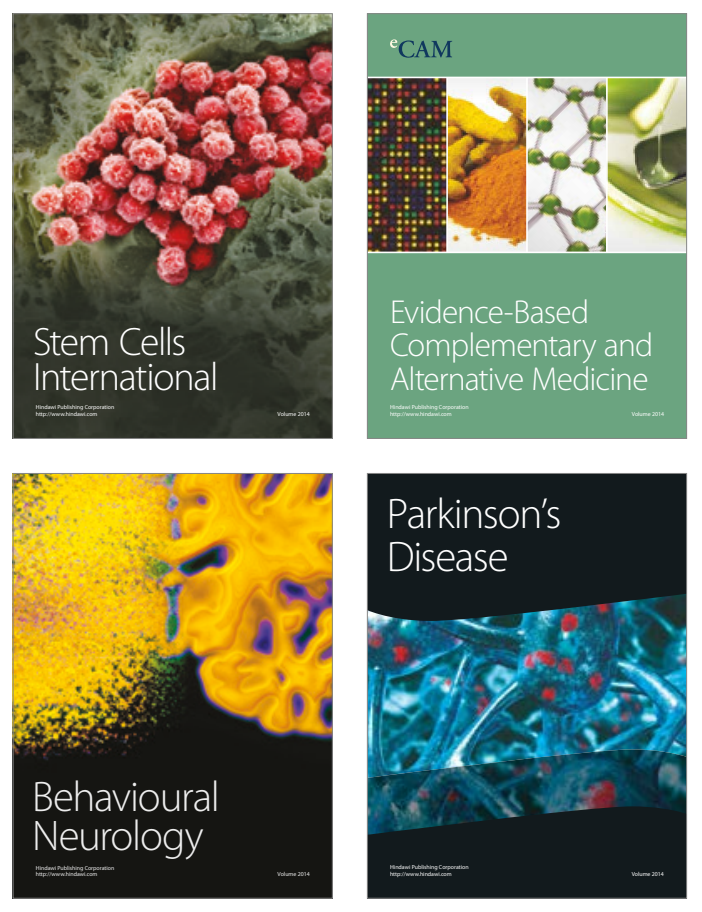
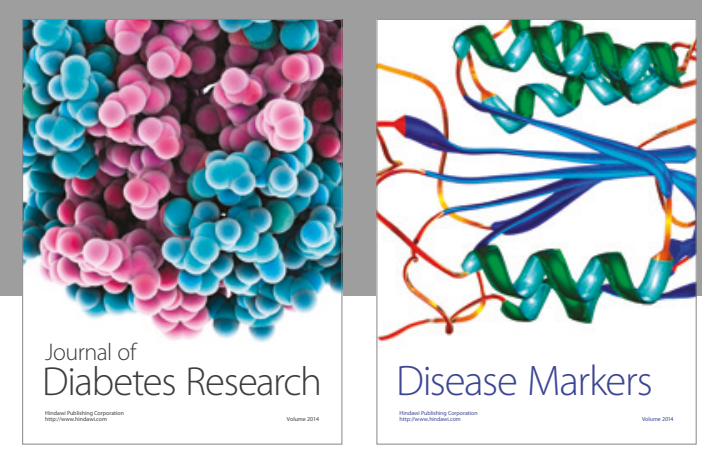

Disease Markers
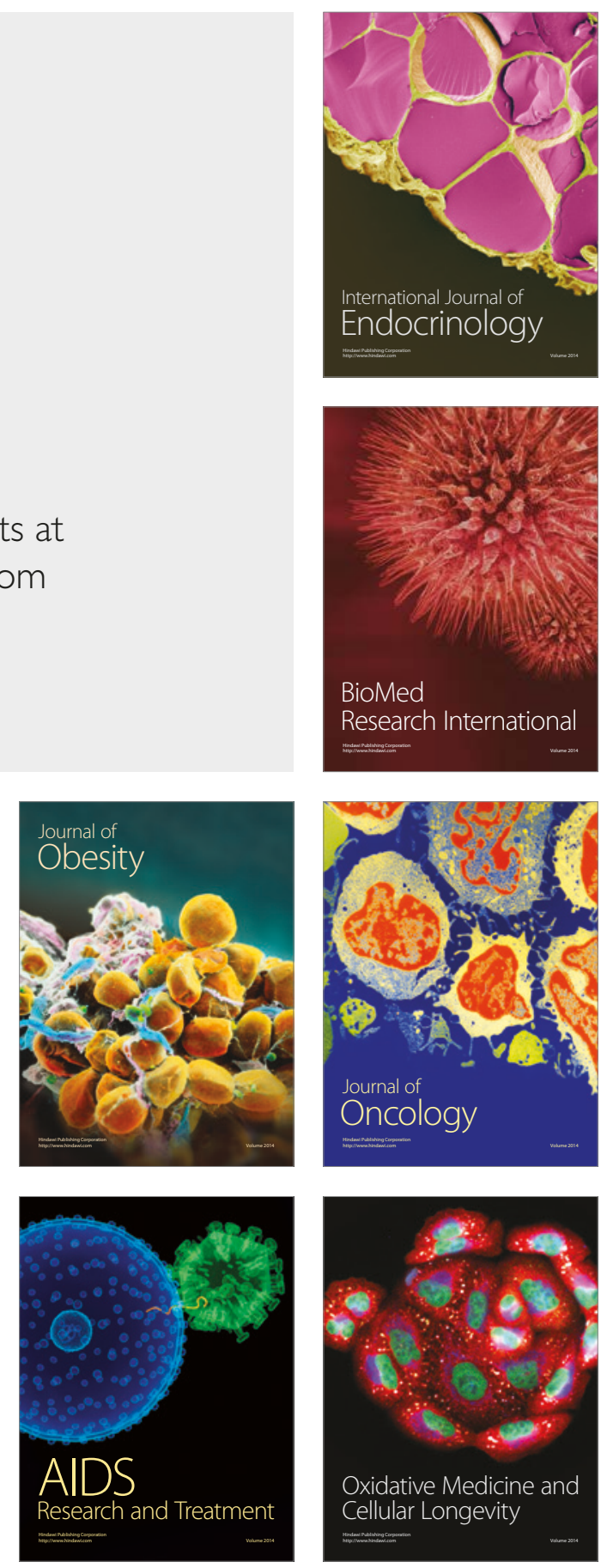